\title{
Bioactive Components and Antioxidant Properties of Terminalia arjuna L. Extracts
}

\author{
Shahzad Ali Shahid Chatha*, Abdullah ljaz Hussain, Rehan Asad, Mudasir Majeed and Nosheen Aslam
}

Department of Applied Chemistry \& Biochemistry, Government College University, Faisalabad-38000, Pakistan

\begin{abstract}
This work was carried out to investigate the antioxidant activity and free radical scavenging capacity of leaves and stem bark extracts of Terminalia arjuna (arjuna) prepared in aqueous ethanol (water: ethanol 20:80v/v) and aqueous methanol (water: methanol 20:80v/v) solvents. The extraction yields of extracts were ranged from $6.66-19.09 \mathrm{~g} / 100 \mathrm{~g}(\mathrm{w} / \mathrm{w})$ on $\mathrm{dry}$ weight basis. It was observed that arjuna extracts contained appreciable amount of TPC $(6.02-11.00 \mathrm{~g} / 100 \mathrm{~g}$, as gallic acid equivalent) and TFC (1.75- $5.96 \mathrm{~g} / 100 \mathrm{~g}$, as catechin equivalent) as well as exhibited good DPPH radical scavenging activity (IC ${ }_{50} 2.71-7.68 \mu \mathrm{g} /$ $\mathrm{mL})$, inhibition of peroxidation (64.79-71.43\%) and reducing power $(0.001-1.584 \mathrm{mg} / \mathrm{mL})$. The results of the present investigation clearly demonstrated the significant $(p \leq 0.05)$ variations in antioxidant properties of different solvent extracts of arjuna. It can be concluded from the results that arjuna extracts were good source of natural antioxidants.
\end{abstract}

Keywords: Terminalia arjuna L.; Total phenolics; IC50; Total flavonoids; DPPH radical scavenging activity

\section{Practical Applications}

The arjuna extracts being a good source of natural antioxidants should be further investigated to explore the chemistry of these extract. In future, these extract can replace the carcinogenic synthetic antioxidants used for the preservation of edible oils and oil/fats based food products.

\section{Introduction}

The antioxidants are molecules capable of decreasing or preventing the oxidation of substratemolecules. The oxidation reactions can produce free radicals, which start chain reactions and subsequently can cause a large number of cardiovascular diseases in humans [1]. Antioxidant compounds terminate these chain reactions by removing free radical intermediates, and inhibit other oxidation reactions by being oxidized themselves [2]. The synthetic antioxidants (butylated hydroxyanisole, butylated hydroxytoluene, tertiary butyl hydroxyquinone and propyl gallate) being used in food products to prevent oxidative damages in terms of food spoilage and rancidity in fatty foods [3] had been band in advanced countries and being discouraged even in developing countries due to their perceived carcinogenic attributes and other toxic properties [4]. Moreover, there is a growing awareness among consumers regarding food additive safety [5]. There is an ongoing quest in progress to search natural antioxidants from plant extracts as a safe alternate of synthetic antioxidants [3]. Many plant based compounds such as ascorbic acid, polyphenols, vitamin E, carotenes, xynthophylls and tannins had been investigated for their antioxidant potential to be used in different food products to improve their shelf life and functional properties [6].

The plant Terminalia arjuna L. commonly known as arjuna, a remarkable tree for its important phytochemicals, belongs to the family combretaceae or the terminalia family [7]. The plant is very rich source of natural antioxidants due to which it has been extensively investigated for its uses in both Ayurvedic and Yunani systems of medicine [7,8]. In Ayurvedic system, it is styptic, anthelmintic, alexiteric, tonic, and useful in fractures, heart diseases, urinary discharges, biliousness, ulcers, asthma, tumors, anemia and excessive perspiration etc. according to the Yunani medicine system [9]. Arjuna is used both externally and internally in gleets and urinary discharges as well as expectorant, aphrodisiac, tonic and diuretic [10]. Terminalia arjuna based phytochemicals are considered as one of the best heart tonic [7] therefore, it can be used on daily bases as tonic for healthy cardiovascular system.

The active components of Terminalia arjuna are tannins, triterpenoid saponin (arjunic acid, arjunolic acid, arjungenin, and arjunglycosides) [11]. Flavonoids (arjunone, arjunolone, luteolin), gallic acid, ellagic acid, Oligomeric Proanthocyanidines (OPCs), phytosterols, calcium, magnesium, zinc and copper [10]. A number of studies are available on the antioxidant activity and medicinal importance of this plant worldwide, whereas, in Pakistan no remarkable research work has been conducted while the plant is easily available due to favorable agro-climatic conditions for its growth. Therefore, this project was designed to investigate bioactive components (phenolics and flavonoids), free radical scavenging property and antioxidant activity of extracts from barks and leaves of arjuna plant indigenous to Pakistan.

\section{Materials and Methods}

\section{Chemicals and reagents}

All the chemicals and reagents used in this research were of analytical grade and used were obtained from Sigma Chemical Co. (St Louis, MO, USA) and used without further purification except some standard reagents, or specified.

\section{Collection and identification of samples}

The bark and leave samples of Terminalia arjuna $L$. were collected

*Corresponding author: Shahzad Ali SC, Department of Applied Chemistry \& Biochemistry, Government College University, Faisalabad-38000, Pakistan, Tel: 92-41-9200671; E mail: chatha222@gmail.com

Received February 04, 2014; Accepted February 18, 2014; Published February 28, 2014

Citation: Shahid Chatha SA, Hussain Al, Asad R, Majeed M, Aslam N (2014) Bioactive Components and Antioxidant Properties of Terminalia arjuna L. Extracts. J Food Process Technol 5: 298. doi:10.4172/2157-7110.1000298

Copyright: (c) 2014 Shahid Chatha SA, et al. This is an open-access article distributed under the terms of the Creative Commons Attribution License, which permits unrestricted use, distribution, and reproduction in any medium, provided the original author and source are credited. 
from the local areas of Faisalabad, Pakistan. The specimens was further identified and authenticated from Dr. Qasim Ali, Assistant Professor of Botany. Authenticated samples of leaves and bark were separately packed in polythene bags and transferred to the Natural Products Research Laboratory, Government College University Faisalabad.

\section{Pre-treatment of samples}

Upon arrival in the laboratory the leaves and stem bark samples were washed thoroughly with tap water to remove any wastes and dust particles. The remaining water in the plant material was removed using paper towel by pressing on them gently. The stem barks and leaves samples were dried by keeping them in open air under shade for three weeks till constant weight was achieved. The dried samples were ground to semi-powder form (10 to 20 meshes) using commercial grinder (TSK-949, WestPoint, France) and were stored in air tight polythene bags in refrigerator at $4^{\circ} \mathrm{C}$ for further analysis.

\section{Preparation of extracts}

Two different solvent systems aqueous ethanol (water:ethanol $20: 80 \mathrm{v} / \mathrm{v}$ ) and aqueous methanol (water:methanol 20:80v/v) were used for the preparation of extracts from the ground bark and leave samples of arjuna. Briefly, 15 gram of ground material was taken in conical flask followed by the addition of $150 \mathrm{~mL}$ of each solvent separately. The extraction was executed for 24 hours in an orbital shaker (Gallenkamp, U.K) at ambient temperature following the previously established method [4]. The residue from the extracts was separated using whatman no 4 filter paper and the crude extract was concentrated using rotary vacuum evaporator (EYELA, N-N Series, Rikakikai Tokyo, Japan) at reduced pressure and elevated temperature $\left(45^{\circ} \mathrm{C}\right)$. The concentrated extract was allowed to dry at room temperature. The dried extract was weighed and stored in refrigerator $\left(-4^{\circ} \mathrm{C}\right)$ in air tight vials. The percentage yield of the extracts was calculated by using the following formula;

$$
\text { Yield }(\%)=\frac{\text { amount of extract }}{\text { dryweight of sample }} \times 100
$$

\section{Estimation of total phenolic contents}

The estimation of total phenolic contents (TPC) was carried out using Folin-Ciocalteu reagent method [12]. Briefly, 50mg of dry mass of extracts was mixed with $0.5 \mathrm{~mL}$ of Folin-Ciocalteu reagent and $7.5 \mathrm{~mL}$ of deionized water. The mixture was kept at room temperature for 10 minutes, and then $1.5 \mathrm{~mL}$ of $20 \%$ sodium carbonate $(\mathrm{w} / \mathrm{v})$ solution was added. Then the mixture was heated in a water bath at $40^{\circ} \mathrm{C}$ for 20 minutes and followed by cooling ice bath. Finally, absorbance at $755 \mathrm{~nm}$ was taken using the spectrophotometer (U-2001, Hitachi Instruments Inc, Tokyo, Japan). The amounts of total phenolic were calculated using a calibration curve Gallic acid (10-100ppm). The results were expressed as Gallic Acid Equivalent (GAE) gram per hundred grams of dry matter.

\section{Estimation of total flavonoids contents}

The total flavonoids contents (TFC) were determined following the previously established spectrometric method [13]. $1 \mathrm{~mL}$ of aqueous arjuna extract containing $0.01 \mathrm{~g} / \mathrm{mL}$ of dry matter was taken in a $10 \mathrm{~mL}$ volumetric flask, then $5 \mathrm{~mL}$ of distilled water was added followed by $0.3 \mathrm{~mL}$ of $5 \% \mathrm{NaNO}_{2}$ solution. After 5 minutes, $0.6 \mathrm{~mL}$ of $10 \% \mathrm{AlCl}_{3}$ solution was added. After another 5 minutes, $2 \mathrm{~mL}$ of $1 \mathrm{M} \mathrm{NaOH}$ solution was added and volume was made up $10 \mathrm{~mL}$ with distilled water. The solution was mixed and the absorbance was measured at $510 \mathrm{~nm}$ using a spectrophotometer (U-2001, Hitachi Instruments Inc,Tokyoa, Japan). TFC amounts were expressed as catechin equivalents per hundred grams of dry matter.

\section{DPPH free radical scavenging assay}

The antioxidant capacities of arjuna extracts were also evaluated by measuring their free radical scavenging abilities to 1,1 -diphenyl-2 picrylhydrazyl (DPPH) stable following the previously established method [14] with slight modifications. The samples (from 6.25 to 100 $\mathrm{mg} / \mathrm{mL}$ ) were mixed with $1 \mathrm{~mL}$ of $90 \mu \mathrm{M}$ DPPH solution and filled up with $95 \%$ methanol, to a final volume of $4 \mathrm{~mL}$. The absorbance of the resulting solutions and the blank were recorded after 1 hour at room temperature. The sample containing butylated hydroxytoulene (BHT) was used as a positive control. All the samples were analyzed in triplicates. The disappearance of DPPH colour was measured spectrophotometrically at $517 \mathrm{~nm}$ using a spectrophotometer (U-2001, Hitachi Instruments Inc, Tokyo, Japan). Inhibition of free radical DPPH in percent (\%) was calculated as;

$$
\text { Inhibition }(\%)=100 \times \frac{A_{\text {blank }-} A_{\text {sample }}}{A_{\text {blank }}}
$$

Where, $\mathrm{A}_{\text {blank }}$ is the absorbance of the control reaction mixture, and $\mathrm{A}_{\text {sample }}$ is the absorbance of the sample. $\mathrm{IC}_{50}$ values, that demonstrate the concentration of extracts that caused $50 \%$ neutralization of DPPH radicals, were calculated from the plot of inhibition percentage against concentration.

\section{Determination of percentage inhibition peroxidation of linoleic acid}

Antioxidant capacities of extracts of were also determined in terms of measurements of inhibition of oxidation in linoleic acid system [6]. 5 $\mathrm{mg}$ of extracts were added to a solution of linoleic acid $(0.13 \mathrm{~mL})$ in 25 $\mathrm{mL}$ volumetric flask and then $99.8 \%$ ethanol $(10 \mathrm{~mL})$ and $10 \mathrm{~mL}$ of 0.2 $\mathrm{M}$ sodium phosphate buffer having $\mathrm{pH}=7$ was added. The mixture was diluted up to $25 \mathrm{~mL}$ with distilled water. The degree of oxidation was measured following ammonium thiocyanate method [15]. $10 \mathrm{~mL}$ of $75 \%$ ethanol (v/v), $0.2 \mathrm{~mL}$ aqueous solution of $30 \%(\mathrm{w} / \mathrm{v})$ ammonium thiocyanate, $0.2 \mathrm{~mL}$ of sample solution and $0.2 \mathrm{~mL}$ of ferrous chloride $\left(\mathrm{FeCI}_{2}\right)$ solution was added respectively. After 3 minutes of shaking, the absorbance of mixtures was measured with spectrophotometer (U-2001, Hitachi Instruments Inc,Tokyo, Japan) at $500 \mathrm{~nm}$ taken as peroxide contents. A linoleic acid control was performed without the extracts. Sample containing synthetic antioxidant, BHT was used as positive control. The prepared samples were incubated at $40^{\circ} \mathrm{C}$ and maximum oxidation level was observed after 360 hours ( 15 days) in the control (blank), sample and positive control. Percent inhibition of linoleic acid was calculated as;

Inhibition of peroxidation ( $\%)=100-\frac{\text { Increase in } \mathrm{A}_{\text {sample }} \text { at } 360 \mathrm{hrs}}{\text { Increase in } \mathrm{A}_{\text {blank }} \text { at } 360 \mathrm{hrs}} \times 100$

Where $\mathrm{A}_{\text {sample }}$ is absorbance of sample and $\mathrm{A}_{\text {blank }}$ is absorbance of blank.

\section{Evaluation of reducing power}

Reducing power of extract was determined according to the procedure described previously [15]. Dry matter extracts $8-12 \mathrm{mg}$ was mixed with $5.0 \mathrm{~mL}$ of sodium phosphate buffer $(0.2 \mathrm{M}, \mathrm{pH}=$ 6.6) and $5.0 \mathrm{~mL}$ of $1 \%$ potassium ferricyanide (w/v) was added, the mixture was incubated at $50^{\circ} \mathrm{C}$ for 20 minutes. Then $5.0 \mathrm{~mL}$ of $10 \%$ $(\mathrm{w} / \mathrm{v})$ trichloroacetic acid was added and centrifuged at $980 \mathrm{~g}$ for 10 
minutes at $5^{\circ} \mathrm{C}$ in a refrigerated centrifuge (CHM-17, Kokusan Denki, and Tokyo, Japan). The upper layer of solution $(5.0 \mathrm{~mL})$ was diluted with $5.0 \mathrm{~mL}$ of distilled water and $1.0 \mathrm{~mL}$ of $0.1 \%(\mathrm{w} / \mathrm{v})$ ferric chloride solution was added. Finally, absorbance at $700 \mathrm{~nm}$ was measured with spectrophotometer (U-2001, Hitachi Instruments Inc, Tokyo, Japan). Sample containing BHT served as positive control.

\section{Statistical analysis}

All the experiments were conducted in three replicates and analyzed in triplicate. The data has been reported as mean \pm SD (standard deviation). Further, the data obtained was analyzed using a statistical technique ANOVA on Minitab software 2002.

\section{Results and Discussion}

\section{Yield of extracts}

The percentage yield of the different arjuna extracts was found in the range of $6.66-19.09 \mathrm{~g} / 100 \mathrm{~g}$ of the dry plant material (Figure 1). It was observed that the stem bark extract prepared in methanol, exhibited the highest yield $(19.09 \mathrm{~g} / 100 \mathrm{~g})$ whereas the lowest one was leaves extract prepared in ethanol $(6.66 \mathrm{~g} / 100 \mathrm{~g})$. Statistical analysis showed the significant $(\mathrm{p} \leq 0.05)$ differences among the extraction yield of two different solvent systems and parts of plant materials. The highest yield of methanolic stem bark extract as established in the present analysis revealed the greater efficiency of methanol as extracting solvent and that might be attributed to the high polarity of the (methanol: water, $80: 20 \mathrm{v} / \mathrm{v}$ ) solvent system. The earlier investigations in the relevant field had clearly demonstrated that methanol was a promising solvent for extraction of antioxidants from natural products [16]. Our results in close agreement to the findings of some previous researcher regarding the yield of extract prepared in different blends of methanol solvent [16]. A raising trend in the yield of antioxidant extracts has been observed with increasing polarity of solvent suggesting the polar natural of antioxidants compounds. Methanol is generally employed for the extraction of antioxidant components due to their polarity and good solubility with many antioxidant components [17]. Ethanol showed relatively low yields as compared to methanol, however, ethanol is even then preferred solvent to extract antioxidant compounds due to it lower toxicity.

\section{Estimation of total phenolic contents}

Total phenolic contents of extracts was determined by FolinCiocalteu reagent due to its high specificity for the polyphenolic compounds present in plant extracts as it did not interact with the other phytochemicals due to a complex formation between reducing species and phosphors-molybdic tungstate. The data regarding the total phenolic contents obtained from different extracts ranged from $6.02-11.00 \mathrm{~g} / 100 \mathrm{~g}$ of plant material, as Gallic Acid Equivalents (GAE) is represented in Figure 2. The maximum amount of TPC (11.00 $\mathrm{g} / 100 \mathrm{~g}$, as GAE) was obtained from arjuna methanolic stem bark extract and the minimum amount of TPC $(6.02 \mathrm{~g} / 100 \mathrm{~g}$, as GAE) was observed in arjuna ethanolic leave extract. The statistical analysis showed the significant differences $(p \leq 0.05)$ in the different arjuna extracts regarding the total phenolic contents among different solvent systems. Our findings regarding TPC of arjuna extracts were found in a close agreement with the findings $(7.8-16.5 \mathrm{~g} / 100 \mathrm{~g}$ of dry matter) as reported by earlier researchers [16]. The $80 \%$ methanol was found more efficient extracting solvent for plant based phenolic compounds as compared to $80 \%$ ethanol. The present results suggested that the methanolic extracts of arjuna are more active regarding the phenolic antioxidant compounds that could be exploited as potent source of natural antioxidants for functional food and pharmaceutics.

\section{Estimation of total flavonoid contents}

The data regarding the total flavonoid contents, $1.75-5.96 \mathrm{~g} / 100 \mathrm{~g}$ of the dry plant material expressed as catechin equivalents is represented in Figure 3. The maximum amount of flavonoids $(5.96 \mathrm{~g} / 100 \mathrm{~g}$, as CE) was obtained from the stem bark extract prepared in $80 \%$ methanol and that of minimum $(1.75 \mathrm{~g} / 100 \mathrm{~g}$ as $\mathrm{CE})$ from leave extract prepared in $80 \%$ ethanol. The statistical analysis showed the significant $(\mathrm{p} \leq 0.05)$ differences in the flavonoids contents among different arjuna extracts in two solvent systems. For extraction of flavonoids compounds, ethanol has been proved very appropriate solvents due to their low toxicity [13]. Extraction yield was dependant on the chemical composition of the bark of tree, as the phenolic and flavonoids contents investigated in the bark extracts Terminalia arjuna from different areas [18]. Our finding regarding flavonoids in the present study were comparable with

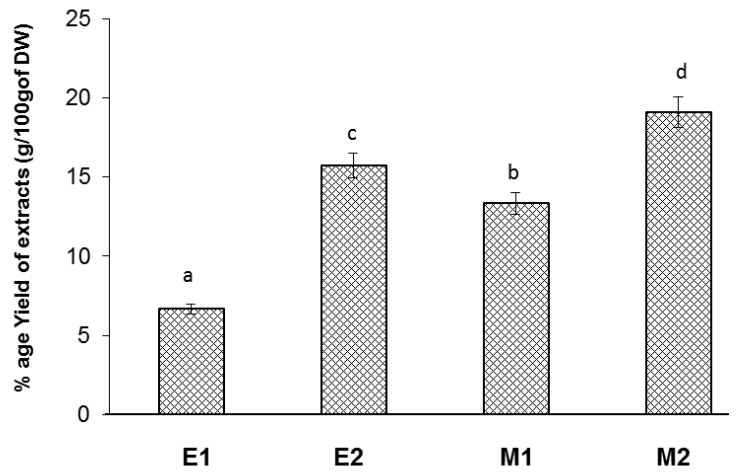

Legend Key: E1= Ethanolic leave extract, E2= Ethanolic stem bark extract $\mathrm{M} 1=$ Methanolic leave extract, M2= Methanolic stem bark extract

Figure1: Percent yield of ethanolic and methanolic extracts of leaves and stem bark of arjuna Different letter on the bars represents significant $(p \leq 0.05)$ difference among different extracts.

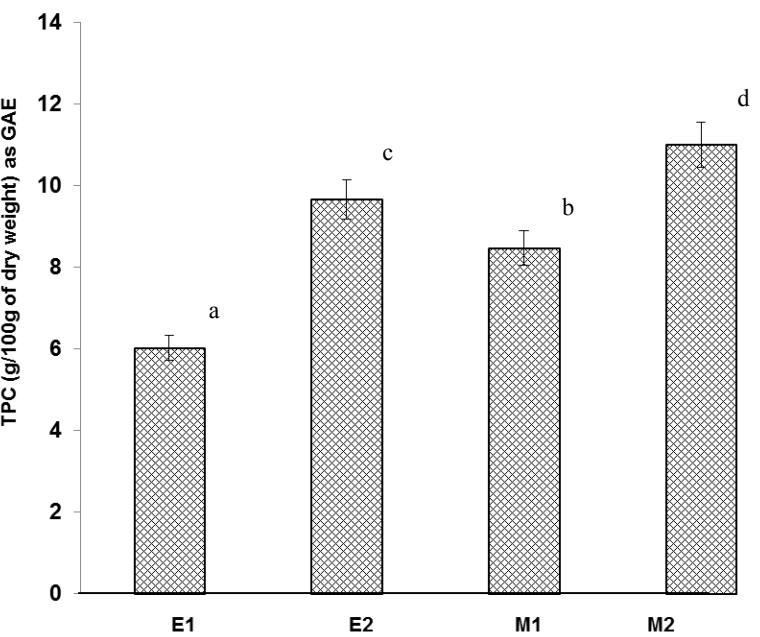

Legend Key: E1= Ethanolic leave extract, E2= Ethanolic stem bark extract, $M 1=$ Methanolic leave extract, $M 2=$ Methanolic stem bark extract

Figure 2: Total phenolic contents of ethanolic and methanolic extracts of leaves and stem bark of arjuna Different letter on the bars represents significant $(p \leq 0.05)$ difference among different extracts. 


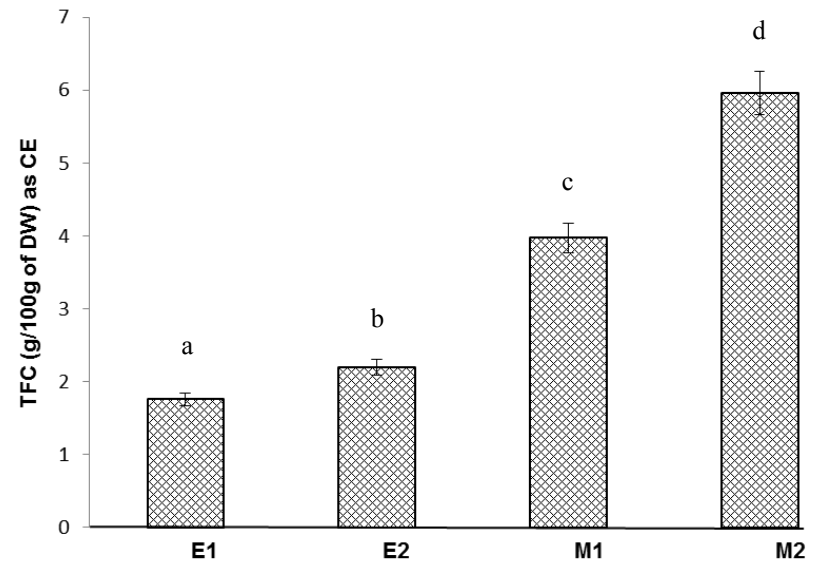

Legend Key: E1= Ethanolic leave extract, E2= Ethanolic stem bark extract, M1= Methanolic leave extract, M2= Methanolic stem bark extract

Figure 3: Total flavonoids contents of ethanolic and methanolic extracts of leaves and stem bark of arjuna Different letter on the bars represents significant $(p \leq 0.05)$ difference among different extracts.

the findings of other researchers [16] worked on antioxidant activity of different plants including Acacia nilotica, Terminalia arjuna, Eugenia jambolana and Azadirachta indica using different solvent blends of ethanol, methanol and water.

\section{DPPH free radical scavenging assay}

Free radical scavenging activity was evaluated using stable DPPH free radical (2-2' diphenyl 1-picrylhydrazyl). Activity of extract increases with the increase in concentration of phenolic compounds. Lower the IC50 values of extract, more effective it will be for inhibition of DPPH free radicals and vice versa. Ethanolic and methanolic arjuna leave and stem bark extracts showed a varied potential of antioxidant capacities in term of IC50 $(\mu \mathrm{g} / \mathrm{mL})$ ranging from $2.71-7.68 \mu \mathrm{g} / \mathrm{mL}$ of different extracts shown in Figure 4 . The IC50 value of $80 \%$ ethanolic stem bark extract of arjuna was lowest IC50 $(2.712 \mu \mathrm{g} / \mathrm{mL})$ showing the highest percent inhibition among all the extracts whereas highest IC50 $(7.684 \mu \mathrm{g} / \mathrm{mL})$ showing the lowest percent inhibition of $80 \%$ ethanolic leave extract. Statistical analysis showed the significant $(\mathrm{p} \leq$ $0.05)$ differences regarding the $\mathrm{IC}_{50}$ value of different extracts. In the DPPH assay, the ability of the examined plant extracts to act as donor of hydrogen atoms or electrons in transformation of DPPH radical into its reduced form DPPH-H was investigated [3].Our findings regarding $\mathrm{IC}_{50}$ values of arjuna extracts can be correlated with $\mathrm{IC}_{50}$ values (16.0$42.1 \mu \mathrm{g} / \mathrm{mL}$ ) those of reported by some other researchers [16].

\section{Percentage inhibition of linoleic acid peroxidation}

The data regarding the percentage inhibition of peroxidation in linoleic acid system from arjuna extracts prepared in different solvent systems is presented in Figure 5. The maximum percent inhibition of linoleic acid peroxidation (78.43\%) was performed by stem bark extracts prepared in $80 \%$ methanol and that of minimum $(61.79 \%)$ by leaves extract prepared in $80 \%$ ethanol. Percent inhibition of linoleic acid peroxidation by synthetic antioxidant (BHT) was taken as control and compared with arjuna extracts. BHT provided significantly higher percent inhibition (91.3\%). Statistical analysis showed the significant $(p$ $\leq 0.05$ ) differences among the extracts regarding percentage inhibition.

Our results are comparable with those ranged from $44.4 \%$ to $90.2 \%$ investigated by earlier scientists [16] on the antioxidant activity of the barks of different plants including Terminalia arjuna $(L)$ by using thiocyanate method [19] reported the \%age inhibition of methanolic extracts which showed higher chelating activity than other samples which showed a good agreement with results given in present research. The results suggested that extracts of (Terminalia arjuna L.) had significant antioxidant capacities and could be explored for use in food and pharmaceutical industries as natural antioxidant.

\section{Reducing power}

The reducing power of a compound is related to its electron transfering ability and may serve as a significant indicator of its antioxidant activity [20]. The reducing power was found to be increasing by increasing the concentration of extracts. The antioxidant compounds in the extract sample that causes the reduction of $\mathrm{Fe}^{3+} /$ ferricyanide complex to $\mathrm{Fe}^{2+} /$ ferrous ions with a change in color from

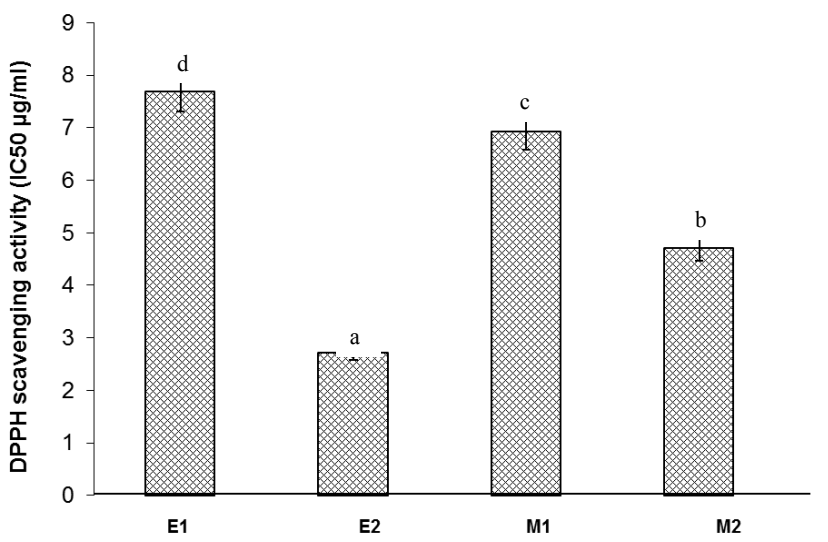

Legend Key: $\mathrm{E} 1=$ Ethanolic leave extract, E2= Ethanolic stem bark extract M1= Methanolic leave extract, M2= Methanolic stem bark extract

Figure 4: DPPH Free Radical Scavenging Activity $\left(\mathrm{IC}_{50} \mu \mathrm{g} / \mathrm{mL}\right)$ of ethanolic and methanolic extracts of leaves and stem bark of arjuna Different letter on the bars represents significant $(p \leq 0.05)$ difference among different extracts.

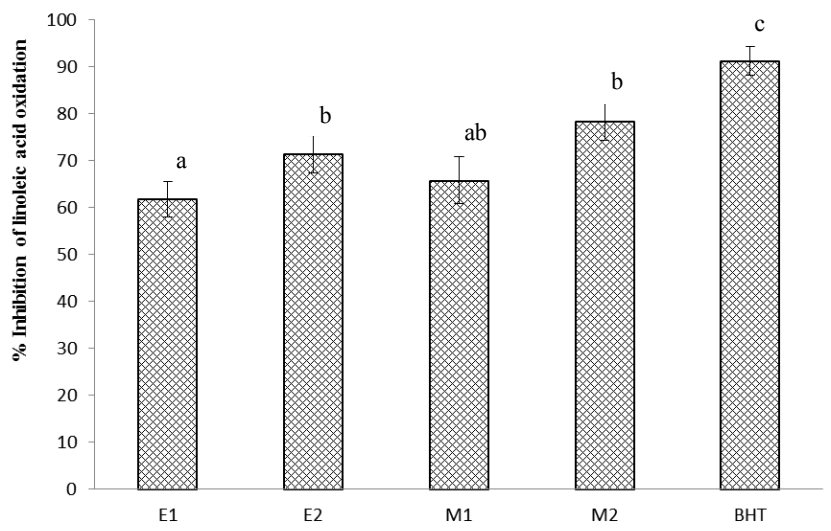

Legend Key: $\mathrm{E} 1=$ Ethanolic leave extract, $\mathrm{E} 2=$ Ethanolic stem bark extract, $\mathrm{M} 1=$ Methanolic leave extract, $\mathrm{M} 2=$ Methanolic stem bark extract

Figure 5: Percentage inhibition of linoleic acid peroxidation with ethanolic and methanolic extracts of leaves and stem bark of arjuna Different letter on the bars represents significant $(p \leq 0.05)$ difference among different extracts. 


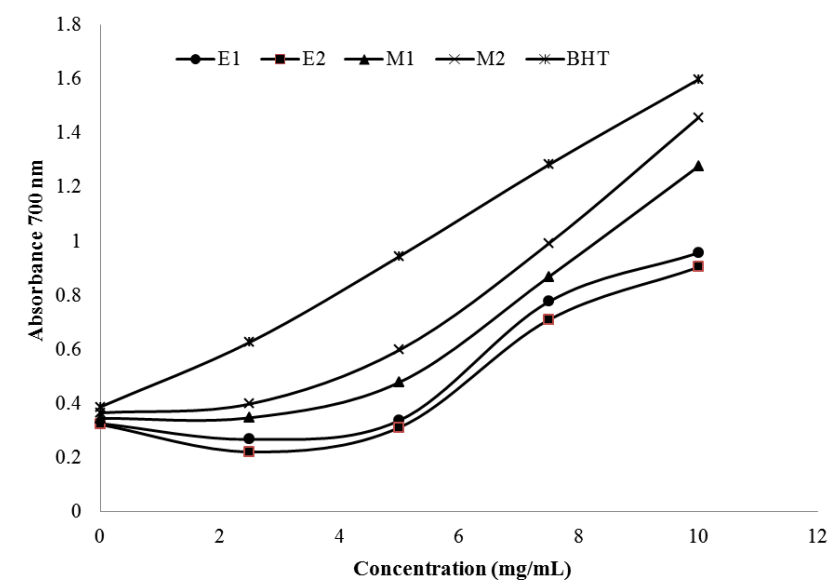

Legend Key: E1= Ethanolic leave extract, E2= Ethanolic stem bark extract, $\mathrm{M} 1=$ Methanolic leave extract, $\mathrm{M} 2=$ Methanolic stem bark extract

Figure 6: Reducing power of ethanolic and methanolic extracts of leaves and stem bark of arjuna at different concentrations.

yellow to bluish green. The different extracts from arjuna exhibited a close dependent reducing power and it was observed that reducing power of extracts from different extracts varied to some extent and found in the range of $0.001-1.584 \mathrm{mg} / \mathrm{mL}$ as presented in Figure 6 . The highest reducing power was exhibited by the stem bark extracts prepared in $80 \%$ methanol and that of lowest stem bark extracts prepared in $80 \%$ ethanol. Statistical analysis showed significant $(\mathrm{p} \leq$ $0.05)$ differences in extracts regarding their reducing powers among different extracts. Our results of present study are in close agreement with the findings $(0.002-1.600 \mathrm{mg} / \mathrm{mL})$ of previous researchers [16]. In the present study, it was observed that methanol was an efficient solvent and stem bark extracts of arjuna were more rich in antioxidant compounds.

\section{Conclusion}

It can be concluded from the results of the present study that the antioxidant activity of Terminalia arjuna L extracts varied considerably depending on the nature of extracting solvents as well as the nature of raw materials to be extracted. The methanol can be exploited for the extraction of effective antioxidant components from the plant material. The arjuna extracts are found to be quite effective in preventing the oxidation. This suggests that extracts of Terminalia arjuna may be explored as a potential source of antioxidants for their use in food and pharmaceutical industries.

\section{References}

1. Chatha SAS, Anwar F, Manzoor M, Bajwa JR (2006) Evaluation of the antioxidant activity of rice bran extracts using different antioxidant assays. Grasas y Aceites 57: 328-335.

2. Chatha SAS, Hussain AI, Bajwa JR, Sagir M (2006) Antioxidant activity of different solvent extracts of rice bran at accelerated storage of sunflower oil. J Food Lipids 13: 424-433.
3. Hussain Al, Anwar F, Chatha SAS, Jabbar A, Mahboob S et al. (2010) Rosmarinus officinalis essential oil: Antiproliferative, antioxidant and antibacterial activities. Braz J Microbiol 41: 1070-1078.

4. Chatha SAS, Hussain Al, Asi MR, Majeed M, lqbal HMN (2011) Evaluation of antioxidant potential of citrus peel extracts. J Cheml Soc Pak 33: 863-867.

5. Khaled T, Alali FQ, Gharaibeh M, Mohammad M, El-Elimat T (2007) Antioxidant activity and total phenolic content of selected Jordanian plant species. Food Chem 104: 1372-1378.

6. Chatha SAS, Hussain AI, Bajwa JR, Sherazi STH (2011) Wheat bran extract: A potent source of natural antioxidants for the stabilization of canola oil. Grasas y Aceties 62: 190-197.

7. Singh UP, Singh DP, Maurya S, Maheshwari R, Singh M, et al. (2004) Investigation on the phenolics of some spices having pharmaco-therapeutic properties. J Herb Pharmacotherapy 4: 27-42.

8. Prakash D, Suri S, Upadhyay G, Singh BN (2007) Total phenol, antioxidant and free radical scavenging activities of some medicinal plants. Int J Food Sci and Nut 58: 18-28.

9. Mukherjee PK, Rai S, Kumar V, Mukherjee K, Hylands PJ, et al. (2007) Plants of Indian origin in drug discovery. Expert Opin Drug Discov 2: 633-657.

10. Kaur C, Kapoor HC (2002) Anti-oxidant activity and total phenolic content of some Asian vegetables. Int J Food Sci Tech 37: 153-161.

11. Biswas M, Kar B, Bhattacharya S, Kumar RBS, Ghosh AK, et al. (2011) Antihyperglycemic activity and antioxidant role of Terminalia arjuna leaf in streptozotocin-induced diabetic rats. Pharmaceutical Bio 49: 335-340.

12. Chaovanalikit A, Wrolstad RE (2004) Total anthocyanins and total phenolics of fresh and processed cherries and antioxidants properties. J Food Sci 69 67-72.

13. Chatha SAS, Arshad MU, Arshad W, Hussain Al, Saif MJ, et al. (2012) Effect of extraction regimes on antioxidant potential of rice (Oryza sativa) bran extracts. J Chem Soc Pak 34: 1290-1294.

14. Bozin B, Mimica-Dukie N, Simin N, Anackov G (2006) Characterization of the volatile composition of essential oil of some lamiaceae species and the antimicrobial and antioxidant activities of the entire oils. Food Chem 54: 1822 1828.

15. Yen G, Duh ED, Lister CE (2000) Antioxidants of anthraquinones and anthrone. Food Chem 70: 307-315.

16. Sultana B, Anwar F, Przybylski R (2007) Antioxidant activity of phenolic components present in barks of Azadirachta indica, Terminalia arjuna, Acacia nilotica and Eugenia jambolana Lam. trees. Food Chem 104: 1106-1114.

17. Siddhuraju P, Becker K (2007) The antioxidant and free radical scavenging activities of processed cowpea (Vigna unguiculata (L.) Walp.) seed extracts. Food Chem 101: 10-19.

18. Silva O, Duarte A, Pimental M, Viegas S, Barroso H, et al. (1997) Antimicrobia activity of Terminalia macroptera root. J Ethnopharmacology 57: 203-207.

19. Choi $\mathrm{Y}$, Jeong $\mathrm{H}$, Lee $\mathrm{J}$ (2007) Antioxidant activity of methanolic extracts from some grains consumed in Korea. Food Chem 103: 130-138.

20. Anwar F, Latif S, Sultana B, Ashraf M (2007) Chemical composition and antioxidant activity of seeds of different cultivars of mungbean. Food Sci 72 : 503-510. 